\title{
Cinco POEMAS de NoITE NU NoRTe, DE FABIÁn SEVERO
}

\author{
FIVE POEMS FROM NOITE NU NORTE, BY FABIÁN SEVERO
}

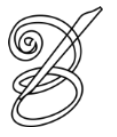 \\ Traduzido por: \\ Fernanda Cristina LOPES* \\ Universidade Federal do Paraná \\ Curitiba, Paraná, Brasil
}

\begin{abstract}
Resumo: Noite nu Norte (2010) é o primeiro livro de Fabián Severo (1981), escritor uruguaio que, desde essa publicação, escreve em portunhol. Essa língua mutável, advinda da invenção-lembrança des(re)territorializa a fronteira entre Artigas e Quaraí, entre Norte e Sul. Ao mesmo tempo, a obra é coetânea de diversas manifestações literárias do portunhol. No que tange à tradução, algumas delas traduziram-se a outra língua por meio da recriação de seu hibridismo, cuja tessitura pode se dar a partir da mescla de elementos do português, do guarani, do castelhano, do inglês, do italiano etc. No caso de Severo, a destruição-invenção da língua tensiona o português e o castelhano e movimenta-se num entre-lugar que pode funcionar de forma diversa em cada leitura. Assim, propomos traduções de cinco poemas de Noite nu Norte a partir da premissa de desestabilizar fronteiras tradutórias entre portunhol e português.
\end{abstract}

Palavras-chave: Fabián Severo. Portunhol. Fronteira. Tradução. Nomadismo.

Abstract: Noite nu Norte (2010) is the first book written by Fabián Severo (1981), a Uruguayan author who, since his first publication, writes in Portuñol. This mutable language comes from the mixture of inventiveness and heritage, which de(re)territorializes the border of Artigas and Quarai, between North and South. At the same time, the work is coetaneous of several literary manifestations of the Portuñol. In regard of the translation, some of them have been translated into another language by recreating their hybridism; its weave can be sewed by combining elements from Portuguese, Guarani, Spanish, English, Italian etc. In Severo's writing, the destructiveinventive relation of the language tensions the Portuguese and the Spanish and moves in an inter-place that can work differently depending on who is reading it. Therefore, we propose translations of five poems from Noite nu Norte based on the premise of destabilizing translation boundaries between Portuñol and Portuguese.

Keywords: Fabián Severo. Portuñol. Border. Translation. Nomadism.

RECEBIDO EM: 10 de janeiro 2020

ACEITO EM: 26 de fevereiro de 2020

PUBLICOU EM: março 2020

LOPES, Fernanda. Cinco poemas de Noite nu Norte, de Fabián Severo. Belas Infiéis, Brasília, v. 9, n. 2, p. 363$370,2020$. 
$\mathrm{F}$ abián Severo (Artigas, 1981), radicado desde 2004 em Montevidéu, é professor de literatura, coordenador de oficinas de escrita e escritor. Publicou diversos textos em sua língua materna, o portunhol, e é autor dos livros de poemas Noite nu Norte (2010), Viento de nadie (2013) e NósOtros (2014) e do romance Viralata (2015), pelo qual recebeu o Prêmio Nacional de Literatura do Uruguai em 2017. Além disso, organizou antologias de novos escritores, sendo responsável pela publicação de alguns livros coletivos como Fruto del desierto (2008) e Huellas de viento en la arena (2009). Parte des de sua obra foram publicadas no Brasil, em Cuba, na Argentina, na Espanha e nos Estados Unidos.

Fernanda Lopes (Curitiba, 1993) é mestranda em estudos literários pela UFPR e tradutora. Recentemente, traduziu um dos contos que integra a obra "As diferentes moradas das palavras: contos de escritoras em tradução" (no prelo, pela Editora da UFPR).

Há 10 anos o livro de poemas Noite nu Norte foi lançado no turbilhão de obras inscritas no movimento amplo do portunhol, língua nômade que se reinventa em cada autor e em cada leitura. No portunhol de Fabián Severo, o espaço fronteiriço - geográfico, simbólico, memorialístico - entre Artigas e Quaraí é o lugar da criação de uma língua. Língua própria,

364 língua materna, língua aprendida fora da escola e que pode ser lida "cantando um idioma/ que todos intende", como se lê no poema Sesenta do livro. O resultado das misturas, sonoridades e sobreposições originadas no encontro do castelhano com o português é a desestabilização. Assim é desenvolvida uma grafia mutante que, dentro de um mesmo poema, pode trazer à tona distintos referentes para as mesmas coisas, colocando-as em movimento. Como pontua Frenkel, tratando de Noite nu Norte e Mar paraguayo (1992), de Wilson Bueno, os multilinguísmos e hibridismos desses textos opõem-se à ideia de língua nacional e configuram espaços literários que abrem espaço à interpenetração e, assim, "[levam] a neutralizar a necessidade de tradução, entendida como conversão semântica e/ou estilística de uma língua a outra, ou como cruzamento de fronteiras" (2016, p. 2300).

A partir do reconhecimento da prescindibilidade da tradução nesses termos, o que propõem estas traduções é justamente um convite à interpenetração: colocar os poemas em movimento dentro da língua de Noite nu Norte por meio da busca por diferentes registros. Isto é, um exercício que desestabiliza x ou y como ponto de partida ou de chegada e encontra linhas de desterritorialização entre o portunhol e as fronteiras de si. Não há ponto de chegada e de partida, e sim pontos de vista. Por essa razão, a seleção dos poemas priorizou aqueles engendram a invenção de uma língua sem dono e, em alguns casos, seu contato incontornável com enquadramentos, barreiras que tentam delimitar um lado e o outro da fronteira. 
Neste conjunto de poemas, Des dá início à transliteração da língua materna. É ela quem "saca la lengua" - seja no sentido de mostrar a língua ao dicionário ou no de tirá-la dele. Na tradução, mostrar acaba por reforçar a escritura transliteradora. Movimento que dança na estabilidade: “[a] língua se estabiliza em torno de uma paróquia, de um bispado, de uma capital"(DELEUZE, 1995, p. 16); em torno de uma escola, também? Dicionarizadamente inscritas, túnica e moña, peças do uniforme utilizado pelas crianças no Uruguai, foram recriadas por calça e blusa.

Já transformadas em pipa, as grafias mutantes de Disesete e Trintisinco levam a cabo a destruição-construção da língua. Nesses poemas, o grafema 'y', por exemplo, joga com fonemas como $/ \mathrm{J} /, / \mathrm{z} /, \mathrm{g} / \mathrm{e} / \mathrm{x} /$ e produz sonoridades vacilantes, produtoras de diferença por repetição. Na tradução, optamos, em muitos desses casos, pelo grafema ' $x$ ' com vistas a propor sonoridades nômades e vacilações e por explorar as relações letra-som de 's' e 'ss', por exemplo. Em outros momentos, uma busca molecular pela oscilação, pelo avesso, norteou algumas escolhas. Um exemplo disso é o verso "Yo impesé sentirme mal" de Trintinove. Empecé, empesé, istá, incontrei. Na tradução, "Eu comenssei a me sentir mal”. Começar, comessar, comencé, empezar. Ou em Sincuentioito, em que a tradução do verso "pero él ni me oia" (de ouvir, se lemos oía; e de olhar, se lemos oia) ficou "pero ele nou ve", propondo o par ouve e vê.

Esses breves comentários ajudam-nos a identificar rupturas em uma falsa contingência: no limite, toda (a) língua é uma invenção. As possibilidades de tradução dessa invenção, no entanto, é o que nos lembra de seu movimento, de sua potência poética. O efeito do portunhol, como propõe Perlongher, “é imediatamente poético. Há entre as duas línguas [o castelhano e o português] um vacilo, uma tensão, uma oscilação permanente: uma é o ‘erro’ da outra, seu devir possível, incerto e improvável." (PERLONGHER, 1992, p. 9). 
Des

Miña lingua le saca la lengua al disionario

baila uma cumbia insima dus mapa

i fas com a túnica i a moña

uma cometa

pra voar

livre i solta pelu seu.

(SEVERO, 2017, p. 19)

\section{Disesete}

Yo no voi pra onde van los ónibus

pos teño medo de no encontrar las cosa que me gustan.

\section{En Artigas \\ por las mañá \\ veyo lamparitas asesas \\ nas puerta con cortina de nailon}

viyilando

Números pintado con cal

nas parede sin revocar

patios de yuyo disparejo

as pileta arrecostada nus alambre pra tender

\section{ropa}

yanelas con maseta rompida

casas pur a metade

$i$ as porta sempre abiertas.

(SEVERO, 2017, p. 26)

\section{Trintisinco}

Mi madre tiña vinticuatro año

i istava yeia de hijo.

No tiña trabajo

nou havía nada pra cumer

i los parente no quirían ayudarla.

Eya me contó que um día

desidió deyarnos nel albergue.

Dis que era um lugar muinto lonye.

Mentras iva nel ónibus

pensava si fasía lo correto.

Des

Miña lingua mostra a lengua pro dissionario

dança una cumbia encima dus mapa

i fas com a calça e a blusa del uniforme

uma pipa

pra voar

livre i solta pelo seu.

\section{Dizessete}

Eu não vo praonde van los ônibus porque tengo medo de não incontra as coisa que eu gosto.

En Artigas

de manhã cedo

vexo as luz acesa

nas puerta con cortina de nailon

i us caxorro deitado

Vixilando

Números pintado con cal

nas parede sein reboco

os quintal con us mato cressido

os tanque incostado nus arame pra

pendurá ropa

janelas com vaso quebrado

casas non termi nada

i as porta sempre abiertas.

\section{Treintaissinco}

Miña mãe tiña vinticuatro ano i tava xeia de filho.

Não tiña trabaio

non tinha nada pra cumer

i los parente não ajudava ela.

Ela mi conto que um día dessidiu dexar agente en el albergue

Disse que era um lugar mui longe.

Dentro del ônibus

pensava se fasia a coisa certa. 
Cuando yegó

la pesoa que la atendéu

dise que no pudía nos tomar

purque la encargada no istava

i que mi madre tiña que voltá nu otro día.

Na volta, eya nos abrasava i yoraba,

arripintida.

Yo diso no me lembro

era mui piqueno.

Ela me dis que si ese día

istuviera la incargada

tudo tenía sido diferente.

(SEVERO, 2017, p. 60-61)

\section{Trintinove}

Solo dos ves yo intré numa mansión.

La primer ves

foi na casa du dotor Cardoso.

Miña main me havía yevado consultá

en uma desas yo me sentí mal

i ele me dise para pasá nu baño,

cuando yo intré incontré dos uater

i pergunté en cuál tiña que haser.

Yo sempre tiña imayinado esas casa.

Mas despós que eu tava ahí

no intendía pra qué tiña tanta piesa.

Havía mucho cuarto

muinto baño

mucho tudo.

Yo impesé sentirme mal

no sé

con vergoña

purque um no istá acustumado con tanto luyo.

La segunda ves

foi na casa del Hugo

ques soldado.

Yo iva fasé mandado

i cuando yeguéi
Cuando xegou

la persona que atendeu ela

dise que não pudía ficar com agente

purque a responsavel não istava

i que miña mãe tiña que voltá nu otro día. Na volta, ela abrassava a gente e xorava, arripindida.

Eu non lembro disu

era muinto chico.

Ela dis pra mim que si nesse día

la responsavel istivesse lá

tudo tiña sido diferente.

Trintainovi

Só duas veces entrei numa mansão.

La primera vez

foi na casa du dotor Cardoso.

Miña main me tiña xevado pra consulta du nada eu me sentí mal

y ele me disse pra i nu bañero,

cuando eu intrei vi dois vaso

i perguntei en cuál tiña que faser.

Eu siempre imaxinei esas casa.

Mas despois qui eu tava alí no intendia pra que que tiña tanta porta.

Tiña mucho quarto

muinto banhero

muito tudu.

Eu comenssei a me sentir mal

sei lá

com vergoña

purque agente non istá acustumado con tanto luxo.

La segunda ves

Foi na casa du Hugo

que és soldado.

Eu ia faze um serviço

i cuando xeguei 
la mujer del me dise que isperara na puerta porque tenía lavado los piso

y yo pudía insusiá.

Eyos tiñan tele

tres en un uno

videocasechi,

en la parede havía um cuadro bein bunito

con dos cavayo

correndo por umas montaña.

Mi casa

la caja de fósforo

no tiña nada diso

el baño ficava afuera

la porta era de lata

el piso de terra

havía un espeio laranya colgado num prego

no havía agua ni yuvero

nos se bañava num latón con agua quente.

Mi madre disía que nos noum se queyara purque cuando era piquena

eya ía se bañar nel río con todos los hermano.

Dis que fasían uma fila

i ivan intrando nel río,

la abuela ía esfregando de a uno.

Mi madre no le gustava

i el frío no se queyava.

(SEVERO, 2017, p. 70-72)

\section{Sincuentioito}

Cuando uno es pobre

i eu so pobre

no puede isquesé de aonde viene.

Asvés yo voi na carnisería

veo el Luisito trabaiando

él me atiende

$i$ yo quero le decir

tú te lembra Luisito

cuando nos iva nel río la mujer dele dise pra ispera na porta

purque ela tiña passado pano

i eu pudía suja o piso.

Eles tiñan tv

tres en um

vidiocasseti,

na parede tiña um quadro bein bunito

com dois cavalo

correndo por las montaña.

Miña casa

a caxa de fósforo

não tiña nada disso

el bañero ficava lá fora

la puerta era di lata

u chão batido

un espelio laranxa que ficava pindurado

num prego

non tiña agua nem xuvero

agente se lavava num latao con agua

quente.

Miña mãe disía pragente non reclama purque quando ela era piquena

ela ia tomá baño nel río con todos os

irmão.

Conta que fasían uma fila

i entravam nel río

la abuela ia isfregando um por um.

Miña mãe não gostava

i el frío não reclamava.

Sincuentaioito

Quando se é pobre

i eu so pobre

não pode sisquese daonde vem.

Asvez eu vou nel assogue

vejo o Luisito trabajando

ele me atende

i eu quero diser pra ele

tú te lembra Luisito

cuando nois ia nel río 
casá vieja del agua

i havía unas

que no largavan las pedra

o cuando nos robava guayavo

da casa da veia Nilda

i ívamos na tua casa

pra cumé guayavo con asúcar

pero él ni me oia.

Después que me da las cosa

dis muchas gracias, el prósimo...

i eu noun sei si ele no se lembra

o no se quiere lembrá.

\section{O la Silvana}

que se foi pra Montivideu

istudiá pra maestra

un día yo crusé con eya nel sentro

ela me miró

i yo levanté la maun pra saludá

i eya deu volta la cara

i se foi.

El que sí se lembra de tudo

es el Manuel

asvés lo veyo sentado por aí

tomando mate

nos botamo a falá daqueles año

i nos matemo de risa.

Qué amigo el Manuel

ese sí no teve sorte

anda camiñando por las caye

sin trabajo i sein familia.

El Manuel se lembra da su sorte.

(SEVERO, 2017, p. 109-111) cassá cascudo

i tiña uns

que non largava as pedra

ou cuando agente robava goyaba

da casa da véia Nilda

$\mathrm{i}$ ia na tua casa

pra cume goyaba com assúcar

mas ele nou ve.

Despois que me intrega las coisa

dis muinto obrigado, quién ta na vez...

i eu non sei si ele não lembra

ou si não quer lembra.

Ou a Silvana

que foi pra Montivideu

istudá pra ser professora

um día incontrei con ela nel centro

ela me viu

i eu levantei la maun pra cumprimenta

ela

e ela viro a cara

i foi imbora.

Mas quein se lembra de tudo

és el Manuel

asvez vejo ele sentado por ahí

tomando mate

a gente cumessa a falá daqueles ano

i nos matemo de rir.

Que amigo és o Manuel

ele sim não teve suerte

anda pra cima e pra bajo

sin trabalho i sein familia.

O Manuel lembra da sua suerte.

\section{REFERÊNCIAS}

BEHARES, Luis E. Transliteraciones fronterizas (Posfácio). In: SEVERO, Fabián. Noite nu Norte/Noche em el Norte: Poesía de la frontera. Montevidéu: Rumbo Editorial, 2011. 
DELEUZE, Gilles. GUATTARI, Félix. Mil platôs: capitalismo e esquizofrenia, v. 1. Tradução de Aurélio Guerra Neto e Celia Pinto Costa. São Paulo: Ed. 34, 1995. p. 16. Tradução de: Mille plateaux.

FRENKEL-BARRETTO, E. Linguagens híbridas para inoperar fronteiras [Uma leitura de Noite Nu Norte e Mar paraguayo]. In: XV Encontro Abralic, 2016, Rio de Janeiro. Anais eletrônicos do XV encontro ABRALIC. Rio de Janeiro: Dialogarts, 2016. p. 2298-2305.

PERLONGHER, Néstor. Sopa paraguaya. In: BUENO, Wilson. Mar paraguayo. São Paulo: Iluminuras, 1992. p. 9.

SEVERO, Fabián. Noite un Norte. Versión anoitesida. Montevidéu: Kapparazón, 2017.

\footnotetext{
* Fernanda Cristina LOPES - Licenciada em Português e Espanhol (2017) pela Universidade Federal do Paraná. Mestranda em Letras na mesma instituição. Universidade Federal do Paraná, Setor de Ciências Humanas, Programa de Pós-Graduação em Letras. Curitiba, Paraná, Paraná. Currículo acadêmico: http://lattes.cnpq.br/9220692316364096 ORCID: https://orcid.org/0000-0003-4767-5374

E-mail: ferncopes@gmail.com
} 